\title{
Uexküll y Merleau-Ponty: una ontología del entre*
}

Uexküll and Merleau-Ponty: An Ontology of the Between

María Luisa Bacarlett Pérez ${ }^{\dagger}$

\begin{abstract}
Resumen
Se propone un recorrido por los algunos de los conceptos centrales de la obra de Jacob von Uexküll, con el fin de establecer su influencia en la propuesta onto-fenomenológica de Maurice Merleau-Ponty. La intención es también mostrar que en ambas propuestas teóricas se configura una ontología peculiar que en lugar de fundarse en sujetos bien constituidos y previos a todo encuentro, parte de las relaciones que estos entablan con su mundo circundante, haciendo de la relación, del entre, lo que define tanto al sujeto como al mundo. No hay, así, sujetos ni objetos previos a las relaciones y composiciones que entablan.
\end{abstract}

Palabras clave: Uexküll - Merleau-Ponty - Umwelt - melodía - ontología del entre

\begin{abstract}
A journey through some of the central concepts of the work of Jacob von Uexküll is proposed, in order to establish their influence in the onto-phenomenological approach of Maurice Merleau-Ponty. The intention is also to show that in both theoretical proposals is configured a peculiar ontology that instead to be founded on well-established subjects, prior of every encounter, part of the relationships that they engage with the surrounding world, making of the relationship, of the between, what defines both the subject and the world. Thus, there are no individuals nor objects previous to the relationships and engagements that they establish.
\end{abstract}

Keywords: Uexküll - Merleau-Ponty - Umwelt - melody - ontology of the between

\footnotetext{
${ }^{*}$ Recibido: 10 de Mayo de 2014. Aceptado en versión revisada: 30 de Julio de 2014.

${ }^{\dagger}$ Facultad de Humanidades, Universidad Autónoma del Estado de México, México. Para contactar a la autora, por favor, escriba a: bacarlett@gmail.com.

Metatheoria 5(1)(2014): 35-47. ISSN 1853-2322.

(C) Editorial de la Universidad Nacional de Tres de Febrero. Publicado en la República Argentina.
} 


\section{Introducción}

La obra y el nombre del etólogo estonio Jacob von Uexküll (1864-1944) resulta poco familiar para el estudioso de la filosofía, sobre todo si no se encuentra cerca de los tópicos ligados a la filosofía y a la historia de las ciencias, su figura e ideas resultan frecuentemente poco conocidas o francamente mal comprendidas. Con todo, hoy sabemos que su obra tuvo alguna influencia -en ocasiones mayor- en filósofos como Ernst Cassirer, Martin Heidegger, Merleau-Ponty, Ortega y Gasset, Jacques Lacan, Georges Canguilhem, Gilles Deleuze o Giorgio Agamben, por mencionar algunos. La razón de tal lejanía y de tal falta de familiaridad reside, fundamentalmente, en el hecho de que Uexküll era finalmente un etólogo, la cuestión salta entonces fácilmente a la vista: ¿qué tiene que decir un etólogo a la filosofía?, ¿qué podría aprender el filósofo de lo que parece ser la mirada pragmática de un científico que estudia el comportamiento animal? Quizá uno de los elementos que actúa a la vez como factor positivo y negativo en la obra de Uexküll es que difícilmente podemos ubicarla en un apartado específico; en tanto filósofo, sus ideas no dejaron de provocar a una tradición de pensamiento centrada en lo que bien podríamos llamar una "ontología fuerte", hecha de sujetos y sustancias bien estructurados y previos a todo encuentro. En tanto biólogo, muchas de sus ideas y experimentos se vieron como críticas a teorías bien aceptadas en su época.

La apuesta del presente artículo es realizar un recorrido por algunas de las ideas centrales del etólogo estonio -el Umwelt, los portadores de significado, la melodía, etc.- y con ello establecer algunos motivos y continuidades con la propuesta fenomenológica de Maurice Merleau-Ponty. Aunque la incidencia del etólogo estonio no siempre fue evidente sobre la obra del francés, ${ }^{1}$ ya desde La estructura del comportamiento se deja sentir el peso de algunas de sus ideas y metáforas. Pero será sobre todo hasta el curso impartido en el Collège de France entre 1957 y 1958, titulado "Animalidad, cuerpo humano y pasaje a la cultura” que las referencias a la obra de Uexküll serán más abundantes. Lo que nos interesa, fundamentalmente, en este artículo es desarrollar tres cuestiones, dentro de las obvias limitaciones de espacio presente: 1) exponer algunas ideas centrales de la propuesta onto-etológica de von Uexküll, 2) revisar la influencia de Uexküll en la obra de Merleau-Ponty y 3) establecer la existencia de una ontología peculiar (lo que he llamado aquí "una ontología del entre") común a ambos autores.

\section{Uexküll: la melodía y el entre}

Aunque las ideas de Uexküll se suelen ubicar en contraposición a las de Darwin, coincidimos con Brett Buchanan (2008) en que el estonio no es necesariamente anti-evolucionista; sin embargo, a lo largo de su obra expone algunas ideas que concibe como crítica a la perspectiva darwiniana. Es claro que en Darwin no encontramos una teoría sobre el origen de la vida, sin embargo la teoría de la evolución contiene una hipótesis fuerte sobre la descendencia de los seres vivos, proceso que a Uexküll le parece muy vertical y excesivamente marcado por el azar. Frente al azar, al estonio le parece más bien que la vida responde a un plan: la forma y posibilidades de los seres vivos se componen melódicamente con la forma y posibilidades de otros seres vivos y con una pluralidad de entes inertes.

\footnotetext{
Uexküll cree firmemente que la naturaleza se conforma a un plan (Planmaßigkeit) donde las cosas orgánicas e inorgánicas se componen entre sí en una gran composición armónica [...].

La perspectiva melódica también lleva a Uexküll a diferenciarse de la teoría evolutiva de Darwin, la cual veía como un modelo "vertical" de descendencia y que enfatizaba demasiado una visión caótica de las formaciones naturales (Buchanan 2008, p. 8).
}

Este es quizá el elemento de la propuesta uexkülliana que más resquemor causó en la comunidad

\footnotetext{
${ }^{1}$ Por ejemplo, en La estructura del comportamiento Uexküll es citado por Merleau-Ponty sólo una vez: "Todo organismo, decía Uexküll, es una melodía que se canta a sí misma" (Merleau-Ponty 1942, p. 172).
} 
biológica que le fue contemporánea: pensar en un plan de organización y de construcción que antecediera a toda relación causal; es decir, el plan -por ende, el rechazo al azar- y la significación como esquemas privilegiados de explicación de lo viviente. Para Uexküll no es el azar sino la conformidad a un plan lo que permite que el organismo y su mundo circundante o Umwelt se ajusten, ese plan está inscrito en el patrimonio genético de cada ser vivo, pero sólo se actualiza y despliega en presencia de un Umwelt que tampoco está dado de manera definitiva antes de su encuentro con el organismo. En este sentido hay un ajuste mutuo, una relación de contrapunto entre Umwelt y organismo, donde lo primordial no son las formas ni los sujetos acabados o previos a todo encuentro, sino el proceso, el devenir, la transformación o el encuentro dinámico entre ambos. No se trata de un encuentro definido por formas dadas previamente, sino es el encuentro lo que da forma a lo que se encuentra. No estamos aquí ante una relación causal-determinista, sino frente a un proceso de regulaciones y acotaciones mutuas que irán en detrimento de una concepción exclusivamente mecánica de la vida.

[Uexküll] No aceptará nunca la reducción del fenómeno de lo vivo a meras ecuaciones matemáticas ni a analogías con lo no-vivo. Su lucha por establecer un puente entre la autonomía de la naturaleza y su descripción constructivista de la auto-organización encierra un fundamento: la regulación como proceso vital (Castro García 2009, p. 97).

Sabemos hoy que la crítica de Uexküll hacia Darwin se debió a una lectura frecuentemente indirecta de la obra del segundo. En gran medida su perspectiva está influenciada por una lectura postdarwinista que hizo énfasis en el azar y el mecanicismo como esquema dominante de la selección natural. Es muy probable que tal lectura de Darwin se debiera al entusiasmo poco riguroso de uno de sus profesores: Julius von Kennel (1852-1939). Darwinista convencido, este profesor de la zoología de la Universidad de Tartu (entonces aquella ciudad de Estonia llevaba el nombre de Dorpat) dio a Uexküll una imagen en extremo simplificada y mecanicista del darwinismo que el alumno rehusó tempranamente. ${ }^{2}$ El rechazo uexkülliano del darwinismo y su insistencia en hablar de un plan de construcción y de significación que guía las relaciones entre organismo y mundo circundante le han valido para situarlo erróneamente dentro de un vitalismo metafísico, postura que el biólogo estonio está lejos de sostener. A pesar de tales asociaciones y malentendidos, la presencia de Uexküll en la biología del siglo XX es innegable, sobre todo como pionero de la etología, "Esto permite que sus investigaciones, que se dirigían a postular un estudio etológico de los patrones de comportamiento animal, anticiparan el trabajo de notables ecologistas como Konrad Lorenz y Niko Tinbergen” (Buchanan 2008, p. 8). Pero el recibimiento de la obra uexküelliana entre los filósofos no será menos contundente, todo lo contrario, posiblemente por su carácter polémico frente a ciertas posturas epistemológicas y ontológicas en boga y que eran sostenidas tanto desde la ciencia como desde la filosofía. Quizá aquello que llamó la atención de algunos filósofos fue que muchas de sus ideas ponen en jaque ciertas categorías centrales de la filosofía occidental, como la de sujeto. Uexküll no duda en llamar sujeto a todo organismo que tiene la capacidad de distinguir y seleccionar un cierto número de señales o portadores de significación entre el abigarrado espacio objetivo que nos rodea (Umgebung); así, un sujeto no es aquel que a partir de la actividad solipsista y voluntaria de su conciencia descubre un mundo y le da forma, sino un organismo que de manera a la vez receptiva y activa se conforma a sí mismo y conforma el ámbito que lo rodea, a través de hábitos y contemplaciones, de afecciones y respuestas, dando lugar a universos subjetivos inconmensurables entre sí, pero que se traslapan y estructuran mutuamente.

Un sujeto es aquello que se estructura en interacción con un mundo circundante, a la vez que éste sólo se vuelve significativo a partir de la actividad y percepción de los sujetos. Si no hay Umwelt sin un sujeto que lo contemple y construya, tampoco hay sujeto sin un Umwelt al cual percibir y construir. Tales ideas Uexküll las desarrolló a lo largo de una obra prolífica, aunque a veces poco conocida, pero sin duda rica en consecuencias para el pensamiento etológico y filosófico posterior: Umwelt und

\footnotetext{
${ }^{2}$ Uexküll estudia zoología en dicha universidad entre 1884 y 1889. Los datos biográficos expuestos en este artículo fueron consultados en Rüting (2004) y en Brentari (2011).
} 
Innenwelt der Tiere (1909), Ideas para una concepción biológica del mundo (1922), Cartas biológicas a una dama (1920 [2014]), Biología teórica (1926), Natur und Leben (1928), Die Lebenslehre (1930), Streifzüge durch die Umwelten von Tieren und Menschen: Ein Bilderbuch unsichtbarer Welten (1934) y Bedeutungslehre (1940).

Así como Uexküll tiene un influjo importante sobre algunos filósofos del siglo XX, de igual forma no fue inmune a recibir influencias filosóficas, de entre todas esas influencias la de Kant es la más significativa, sobre todo porque partiendo del giro copernicano que implica la obra kantiana, Uexküll está perfectamente de acuerdo con el principio que nos dice que no encontramos en la naturaleza más que lo que hemos puesto previamente en ella. "Kant nos mostró que el mundo circundante es nuestro mundo perceptible y sus rasgos fundamentales sólo pueden ser reconocidos correctamente cuando las formas que les imprime nuestro punto de vista subjetivo se manifiestan” (Uexküll 1913, p. 188). Lo que hay, el mundo y los sujetos que lo habitan, son producto del encuentro de los seres vivos que contemplan y actúan sobre un mundo que configuran a partir de sus percepciones, a la vez que este mundo configura la estructura de los organismos a partir de lo que ellos contemplan y privilegian como significativo. Si para Kant toda realidad es apariencia subjetiva, para Uexküll hay tantos mundos como maneras de percibir y de habitar; es decir, la realidad que conocemos y de la que tenemos experiencia es, en última instancia, aquella que subjetivamente percibimos. Claro está que Uexküll lleva la apuesta kantiana al extremo, pues para él no sólo se trata de la percepción humana, sino la de todo ser vivo. No hay, por tanto, un mundo objetivo válido para todas las formas de percibir (a este mundo objetivo nos referimos con el término alemán Umgebung), no hay un único mundo allá afuera del cual la ciencia, como única mirada objetiva, podría darnos cuenta. Al contrario, hay tantos mundos como maneras de contemplar y actuar sobre la realidad, y cada mundo comprende aquellos elementos que para cada sujeto son significativos. A cada sujeto, pues, le envuelve un mundo circundante o Umwelt a partir del cual cada uno percibe -a través de la contemplación, de la actividad también- lo importante, lo significativo, lo existente. Pero de la misma forma, "[...] cada símbolo de significación de un sujeto es al mismo tiempo un motivo de significación para la estructuración del propio sujeto" (Uexküll 1942, p. 170). Así, el mundo circundante es una construcción del sujeto, en tanto se reduce a aquello portadores de significado que son relevantes para él; pero al mismo tiempo, el sujeto se estructura en consonancia con su Umwelt, a partir de los portadores de significado que comprenden dicho mundo circundante.

Pero podría afirmar que la naturaleza entera participa como motivo en la formación de mi personalidad física y espiritual, ya que si tal no fuera el caso, yo no tendría órganos para conocer la naturaleza. Puedo exponer esta proposición más modestamente y decir: yo no participo en la naturaleza más que en la medida en que ella me hace entrar en una de sus composiciones (Uexküll 1956, p. 162).

De esta manera, para que algo se convierta el portador de significado debe haber un órgano que permita percibirlo: ¿podríamos percibir la luz del sol sin ojos? Nosotros, por ejemplo, poseemos un órgano por el cual podemos percibir la luz solar y por ello ésta forma parte de nuestro Umwelt; así, luz solar y ojo entran en una relación de contrapunto en la cual uno es para la otra y viceversa: la luz solar tiene cabida en mi Umwelt en tanto es percibida por mi ojo y en tanto es motivo para la estructuración de mi ojo. No es que mi ojo cause la luz solar, tampoco la luz solar es la causa eficiente de la producción de mi ojo. Para que tal relación de causa-efecto fuera de inicio posible, la luz solar o mi ojo tendrían que tener una existencia en sí, independiente de toda relación; sin embargo, ¿la luz solar existe como portador de significado para todo organismo?, ¿tiene para todo organismo el mismo significado?, ¿todo órgano de la visión percibe la luz solar de la misma forma? No hay luz solar en sí, ella forma parte de mi mundo circundante en tanto puedo percibirla con mi ojo, un órgano cuya estructura le permite percibir no sólo la luz solar sino muchos otros portadores de significado (colores, sombras, formas, profundidad, volumen, etc.). Tampoco hay un ojo en sí, sino sólo un órgano que permite percibir ciertas cosas y de cierta manera. Si de pronto desaparecieran de la faz de la tierra todos

${ }^{3}$ Esta obra fue publicada junto a Georg Kriszat. 
los organismos que tienen ojos, el sol no desaparecería, su luz no podría ser percibida, pero el calor que el sol desprende seguiría formando parte del mundo circundante de muchas otras formas de vida.

\begin{abstract}
Sabemos que este sol, este cielo y esta tierra desaparecerán con nuestra muerte y continuarán viviendo en formas semejantes en los mundos circundantes de las generaciones venideras.

[Hay así una] diversidad de mundos circundantes, en los cuales las cosas se repiten en formas siempre nuevas (Uexküll 1942, p. 172).
\end{abstract}

Esto nos lleva a reparar de nuevo en el claro talante anti-antropocéntrico en la propuesta uexkülliana. No hay un solo mundo, es decir, el humano, sino una pluralidad de mundos -el de la garrapata, el de la mosca, el del perro, el de la araña, etc.- en donde cada uno tiene tanta perfección y complejidad como el otro. A cada sujeto, pues, le envuelve un mundo circundante a partir del cual cada uno establece -a través de la contemplación, de la percepción, de la actividad también- lo importante, lo significativo, lo existente. La etología uexkülliana nos transporta a un universo hecho de miles de esferas o pompas de jabón (Seifenblase) ${ }^{4}$ dentro de cada cual los sujetos que las habitan construyen su mundo y se construyen a sí mismos a partir de tal relación. La dificultad de dar cuenta de tal concepción del sujeto y del mundo circundante es que ambos términos no pueden concebirse separadamente. El mundo circundante se parece pues a una esfera imaginaria construida alrededor del animal, dentro de la cual sólo existen aquellas cosas que son significativas para él, fuera de cuyo perímetro está lo que no existe, es decir, lo que no puede ni ver ni percibir. Cada mundo es, así, el producto de la perspectiva del sujeto que lo habita y de que dota a sus elementos de cierto significado; pero de igual manera, cada ser vivo se constituye como sujeto a través de la manera cómo percibe, actúa y se acopla a su medio significante.

Para Uexküll, mientras desde la perspectiva mecanicista el ser vivo responde a un plan centrípeto donde es el ambiente lo que le impone sus directrices y posibilidades, desde la perspectiva del etólogo estonio, los límites y posibilidades tanto del organismo como de su medio circundante se establecen en la relación o ligazón entre ambos. Cada viviente, al vivir en su propio medio o burbuja de jabón, hace un corte en el caos para establecer lo que para él es significativo, claro está que el medio regresará sobre él influyendo en su conducta, sus respuestas y hasta en su estructura física. Pero lo importante a destacar aquí es el elemento relacional que sirve como pivote de uno y otro. Estamos así, ante una perspectiva onto-etológica en la cual no hay sujetos ni objetos propiamente dichos, sólo relaciones.

No hay una relación determinista ni lineal entre organismo y mundo, es decir, si bien el organismo no existe de manera independiente a su mundo circundante, éste sólo tiene realidad dentro de la perspectiva de aquél. ${ }^{5}$ La relación entre Umwelt y organismo se parece en mucho a una melodía que es producto del contrapunto entre dos notas particulares, ya que si una de éstas deja de emitir su sonido, entonces la melodía no resulta. De esta manera, la naturaleza estaría hecha por diversas notas que entrarían en contrapunto y darían lugar al mundo natural, la conjunción y complementación de todas

\footnotetext{
${ }^{4}$ El término "pompas de jabón" -en alemán, Seifenblase- es utilizado por el propio Uexküll en una de sus obras más conocidas, Streifzuge durch die Umwelten von Tieren und Menschen (1956), ahí aparece en ocho ocasiones, en las páginas 22 y 46. También se puede encontrar en dos artículos: "Die Einpassung" (1927), publicado en el Handbuch der normalen und pathologischen Physiologie, y "Die Rolle des Subjekts in der Biologie" (1931), publicado en Die Naturwissenschaften.

5 Aquí pusimos en cursivas dos términos de gran importancia dentro del presente artículo. Consideramos que desde la perspectiva de Uexküll son, además, dos conceptos que se contraponen. Por "determinismo" nos atenemos aquí a la concepción clásica del mismo que lo liga a una perspectiva mecanicista; nos referimos con ello a la postura según la cual "[...] todo evento o estado de cosas es causado por eventos anteriores o por estados de cosas a partir de las leyes causales del universo que gobiernan el mundo. De manera que el estado del mundo en cualquier instante determina un futuro único; así, el conocimiento de todas las posiciones de las cosas y las fuerzas naturales prevalecientes permitirían predecir el futuro estado del mundo con absoluta precisión” (Berofsky 1999, p. 228). En Uexküll, las relaciones entre organismo y mundo no son deterministas, pues ni el medio puede establecer con absoluta precisión la respuesta ni la forma del organismo, ni éste conforma de manera definitiva las posibilidades del medio. El viviente entra con el medio en una relación compleja donde la forma y directrices del medio no se plasman linealmente en aquél, sino que ellas dependen de la perspectiva, o para usar un término merleau-pontyano, de la percepción del viviente. En este punto, el rechazo al determinismo mecanicista es notablemente parecido tanto en Uexküll como en Merleau-Ponty: "Cada organismo tiene, en presencia de un medio dado, sus condiciones de actividad, una manera propia de realizar su equilibrio, y los determinantes interiores de este equilibrio no son dados por una pluralidad de vectores, sino por una actitud general en relación al mundo" (Merleau-Ponty 1942, p. 161). En suma, no es el medio el que determina las posibilidades del organismo, antes bien, es el propio organismo el que establece desde su propia perspectiva -o percepción- la manera como el medio actúa en él.
} 
la notas darían lugar a una gran sinfonía que sería la naturaleza misma; pero lo interesante es reparar en que la melodía no remite ni a un punto, ni a un sujeto, ni a una nota aisladamente, remite a la relación, al entre. ${ }^{6}$ Ese es precisamente uno de los elementos más interesantes e innovadores que propone Uexküll y que, para el otro autor que aquí nos convoca, Merleau-Ponty, resulta capital para su propia empresa filosófica. Efectivamente, en la etología uexkülliana los sujetos no preceden a las relaciones que los conforman, no hay sujeto antes de entrar en contacto con su medio, con otros objetos significativos y con otros sujetos, es como si la otredad fuera intrínseca a cada ser vivo. Como lo expresa Buchanan: "En el fondo, un organismo es lo que es capaz de devenir, de modo que es ya otro en el que se convierte en esta armoniosa relación” (Buchanan 2008, p. 34).

Lo que expone Uexküll es que para dar cuenta de un ser vivo no hay que preguntar qué es, sino qué puede, -en términos deleuziano-spinozistas- con qué puede conectarse, relacionarse. No hay sujeto previo a las relaciones que entabla, a aquello que lo afecta, por ello mismo, cada sujeto es los acoplamientos que lleva a cabo, los afectos que padece y produce. El sujeto deja de ser así una sustancia o una conciencia previa a todo encuentro, deja de ser presupuesto y fundamento, para encontrarse al final, no al principio; nunca acabado ni terminado, sino siempre rehaciéndose, en el entre. Este debilitamiento del sujeto, y con él de un caudal de categorías ontológicamente fuertes, pone en jaque también nuestra creencia en la existencia de un único sujeto, el hombre; éste, al igual que el perro o la garrapata, es un sujeto más, que se conforma con cada nuevo encuentro, con cada nueva afección y acoplamiento. Como hemos visto, el etólogo recurre a la figura de la melodía para explicar cómo emerge tanto la estructura de los organismos como la estructura del Umwelt: en el contrapunto, en el encuentro de dos ejecuciones, de dos partituras. Serán estas dos figuras, la del entre y la de la melodía, lo que aparecerá de manera directa o indirecta en buena parte de la obra merleaupontyana.

¿Cómo es posible que dos cosas de tan diferente origen como, por ejemplo, el abejorro y las flores de diente de león, de tan diferente estructura, se adapten entre sí en todas sus particularidades? Evidentemente a causa de que ambas melodías de la forma se influyen mutuamente: a causa de que la melodía del diente de león interviene como motivo en la melodía del abejorro, y viceversa. Lo que es

\footnotetext{
${ }^{6}$ Puede resultar polémico que Uexküll utilice el término "melodía” en lugar del de "armonía", en tanto el primero hace más bien referencia a una sucesión temporal de notas, mientras que el segundo refiere a la simultaneidad de al menos dos notas, a la combinación de sonidos simultáneos pero diferentes. Lo mismo pasa con el término "contrapunto" que bien puede definirse como "La habilidad de decir dos cosas a la vez de manera comprensible [...]. Una sola parte o voz agregada a otra se llama 'contrapunto', pero el uso más común de la palabra refiere a la combinación de partes simultáneas, cada parte puede ser significativa en sí misma, pero el todo resulta también en una textura coherente. En este sentido, el contrapunto es lo mismo que la polifonía" (Kennedy, Kennedy \& Rutherford-Johnson 2013, p. 165). Así, el concepto "contrapunto" es claramente más afín a la idea de armonía que a la de melodía y, sin duda, la relación que Uexküll quiere subrayar entere los seres vivos y entre estos y su ambiente se ajusta más a un esquema melódico de contrapunto, pues lo que quiere mostrar es que las notas no se suman de manera sucesiva, como si se tratara de la agrupación de elementos separados, sino que cada nota se incorpora a la otra, se combina con la otra, se presenta como un motivo que constituye a la otra. Sin embargo, en este texto nos restringiremos al término que Uexküll utilizó en alemán: Melodie. Como lo aclara Donald Favareau, Uexküll se vale de ciertos términos musicales como metáforas ante lo que considera un déficit de la terminología tanto biológica como filosófica de su época, por lo cual, es probable que en tanto metáforas no se usen exactamente con el mismo sentido con el que originalmente se usan en la música, es probable, así, que el uso de una palabra como Harmonie hubiera sido el más indicado, sin embargo, Uexküll opta por usar el término Melodie y ligarlo a otros conceptos que se encuentran estrechamente relacionados a lo largo de toda su obra: sonido, teclado, motivo, contrapunto, composición, etc.: "En el contexto de la semiótica, es de interés poner atención en un aspecto de su metodología [de Uexküll], su uso muy frecuente de metáforas musicales. Esta práctica era muy común entre los biólogos románticos. [...] en los escritos de Uexküll metáforas como tono, piano, melodía, motivo, contrapunto, composición y otras, perecen jugar un rol particularmente importante. [...] En tanto no conoce otros términos de la semiótica o de la humanidades, usa términos de la música para este propósito" (Favareau 2010, p. 424). Hemos decidido, por tanto, en este artículo, respetar el término que originalmente utilizó Uexküll en alemán, sabiendo que dentro de la estricta terminología musical no es el más adecuado. En el libro de 1913, Bausteine zu einer biologischen Weltanschauung, pero sin duda en el resto de su obra, Uexküll deja clara la elección de dicho término, sobre todo cuando trata de contrastar la aparente perfección de estructuras biológicas como los genes, el plan o el protoplasma y su expresión real, misma que compara a la ejecución de una melodía o de una sonata: "So sind die organischen Faktoren, die wir bei der Entwicklung bisher kennen gelernt haben: Gene, Plan und Protoplasma - Noten, Melodie und Klavier. Gene und Plan scheinen stets ganz tadellos zu sein, nur bei ihrer Einwirkung auf das Protoplasma können Störungen vorkommen, die wir experimentell ausnutzen; - wie eine Sonate Beethovens, die auf dem Papier tadellos ist, in ihrer Ausführung auf dem Klavier aber oft recht viel zu wünschen übrig lässt” (Uexküll 1913, p. 175, las cursivas son nuestras). (“Así son los factores orgánicos que hasta ahora hemos conocido en la evolución de genes, plan y protoplasma: notas, melodía y piano. Genes y plan parecen ser siempre perfectos; sólo en su actuación sobre el protoplasma pueden presentarse perturbaciones que aprovechamos experimentalmente, como una sonata de Beethoven, que es perfecta en el papel, pero que deja mucho que desear en su ejecución en el piano").
} 
válido para la abeja lo es también para el abejorro, y si su organismo no fuese propio para la flor no se hubiese logrado su estructura (Uexküll 1942, p.163).

No es que el mundo esté allá afuera esperando a que los seres vivos se adapten a él, antes bien, cada organismo entra en relación con una parte muy pequeña del entorno, se crea un mundo circundante por la manera como se relaciona con él, creando un ámbito único y propio de él. Renuente a aceptar cabalmente la perspectiva darwinista, Uexküll apuesta, no por la selección del más apto, sino por la selección del adaptado, es decir, "la naturaleza no escoge a los organismos adaptados a ella, sino que cada organismo escoge la naturaleza a él adaptada” (Uexküll 1913, p. 21).

Como hemos repetido, en la etología uexkülliana los sujetos no preceden a las relaciones que los conforman, no hay sujeto antes de entrar en contacto su mundo, con otros objetos significativos y con otros sujetos, es como si la otredad fuera intrínseca a cada ser vivo. Es decir, la abeja -trayendo a cuenta el ejemplo citado más arriba- no es una entidad fija y dada de una vez por todas, es abeja por las conexiones que establece, para usar un término deleuziano, por los agenciamientos que entabla, no es un punto sino una línea que la conecta a otra cosa, es el devenir que conforman todas sus interacciones. Como lo expresa Buchanan: "en el fondo, un organismo es lo que es capaz de devenir, de modo que es ya otro en el que se convierte en esta armoniosa relación” (Buchanan 2008, p. 34). Uexküll está hablando de una intencionalidad animal no mediada por la conciencia a la manera husserliana, pero que se plasma sin embargo en la estructura del organismo.

\section{Merleau-Ponty: el entre y el comportamiento}

Merleau-Ponty entra en contacto por vez primera con la obra de Uexküll, en La estructura del comportamiento de 1942. Aunque en este libro lo menciona en una sola ocasión, su presencia es innegable en toda la obra del filósofo francés. Es también en este libro que también aparece otro pensador notable y que destaca por su cercanía con muchas posturas uexküllianas, nos referimos a Kurt Goldstein (1878-1965). Su trabajo más importante, La estructura del organismo, publicado en 1951, se suma a la perspectiva de la psicología Gestalt de la que el propio Merleau-Ponty es heredero. En esta obra Goldstein defiende una concepción holista del organismo que trata, sobre todo, de superar las clásicas explicaciones mecanicistas respecto a la vida, mismas que tienden a dar una imagen parcelada del viviente, una figura hecha de partes extra partes a partir de la cual ha sido posible tanto el localizacionismo médico como el modelo biológico-lesional. El neurólogo y psiquiatra alemán tuvo la oportunidad de atender a una gran variedad de soldados heridos en la Primera Guerra Mundial, muchos de ellos afectados por lesiones en la cabeza. Goldstein encuentra que aunque las lesiones afecten zonas bien precisas del cerebro, los daños en el funcionamiento del organismo no competen ni a una sola habilidad ni a una sola región: "Para nosotros, la localización de una operación no significa la excitación de un espacio determinado, sino un proceso dinámico que se despliega en todo el sistema nervioso e incluso en el organismo entero [...]" (Goldstein 1951, p. 220). Esta perspectiva holista atravesará la obra de Merleau-Ponty de principio a fin: aquello que ocurre en el organismo no es producto de estímulos aislados, sino de una estructura compleja y relacional que pone en consonancia al organismo entero para dar una respuesta, para dar sentido a un estímulo en particular. En su acercamiento a Goldstein, Merleau-Ponty no duda en utilizar también la metáfora de la melodía: este estímulo en concreto, esta reacción en concreto -pensemos en las lesiones de bala en la cabeza de muchos soldados- no es el efecto de haber dañado una zona específica del cerebro, sino la respuesta de un todo; así, no es sólo un instrumento de la orquesta el que es afectado, sino es toda la orquesta la que entra en una composición diferente, lo cual tendrá como consecuencia que no podrá ejecutar la misma melodía. La lección que Merleau-Ponty retiene de Goldstein es muy clara: si toda respuesta del organismo implica a la totalidad del mismo y no a parcelas aisladas, si no hay una localización tajante y atómica entre estímulo y respuesta, si el organismo responde siempre como un todo, entonces ningún estímulo y ninguna reacción preexisten al encuentro que se da entre ambos. Dicho de otra manera, no hay una relación determinista entre estímulo y respuesta porque ambas dependen de la estructura del 
organismo, de cómo se configura ese todo en cada respuesta, en cada percepción, en cada estímulo. En suma, no hay ni estímulos ni percepciones a priori, ambos se constituyen en la relación, en el entre, en el momento de percibir e interpretar eso que viene de fuera - un color, un sonido, una bala. En términos más uexküllianos, bien podríamos decir que ni el organismo ni el medio se preceden uno a otro, antes bien, entre ambos se abre una verdadera zona de indiferenciación que nos permite ver a ambos como "una estructura unitaria que debe considerarse en forma holista" (Ostachuk 2013, p. 51).

$\mathrm{Al}$ rechazar un determinismo lineal entre estímulos exteriores y respuesta del organismo, estamos también reconociendo la capacidad perceptiva de este último, su capacidad de elaborar aquello que le viene de fuera. Goldstein compartiría con el francés y el estonio tal perspectiva: "[...] la excitación no sería jamás el registro pasivo de una acción exterior, sino la elaboración de estas influencias sometidas a las normas descriptivas del organismo" (Goldstein 1951, p. 29). El organismo, en este sentido, no sería una unidad en virtud de que posee un cuerpo, de que es una estructura material, más bien, su unidad le vendría de su comportamiento, de la manera como elabora y da sentido a los estímulos exteriores, en el entendido de que esta elaboración rompe con toda perspectiva determinista y mecanicista, pues su unidad está garantizada por la dinámica de su estructura, de sus relaciones tanto al interior del mismo como con el exterior. En este talante, el organismo es sólo en las relaciones con su medio, no es algo que se conforma a priori a todo encuentro o a toda relación, antes bien, es su comportamiento, eso que emerge entre él, el mundo y su manera de percibirlo, de darle sentido. Goldstein no niega que el organismo esté conformado por estructuras que implican una función o una percepción determinada, sin embargo, esta especificidad se debilita o anula en tanto toda parte del organismo está conectada o en consonancia con otras, está siempre en relación, de una forma u otra, con otras partes del mismo: "[...] la especificidad sólo puede nacer, de alguna manera, en la operación que es llevada a cabo por la totalidad del organismo y que recibe de cada parte una coloración cualitativa bien determinada según la operación en cuestión" (Goldstein 1951, p. 231).

Una zona específica del cuerpo vivo puede ser afectada, pero la respuesta incumbe al todo. No hay, así, un determinismo lineal del exterior sobre el organismo, sino éste, como melodía que se canta a sí misma, es el resultado de una complementación y co-constitución de notas, de sonidos, de partituras, que sin dar lugar jamás a la misma melodía, no pueden dejar, sin embargo, de componer una, hecha de interrelaciones, contrapuntos y configuraciones únicas. La metáfora musical vuelve a la carga para sortear cualquier forma de determinismo mecánico y para fundamentar la concepción de un organismo relacional, que se extiende más allá de lo materialmente actual y específicamente local.

Fenomenología de la percepción tampoco será abundante en citas a Uexküll; sin embargo, la figura del entre, la apuesta por una ontología relacional, aparecerá de nuevo, sobre todo al problematizar la cuestión del cuerpo y del tocar -tema que después desarrollará de manera magistral Jean-Luc Nancy en obras como Corpus (2003)-, en particular en la imagen del quiasmo y del cuerpo quiasmático. Es precisamente con el concepto de quiasmo que Merleau-Ponty trata de dar cuenta del umbral de indiscernibilidad abierto entre el cuerpo y el mundo, entre la carne y el mundo, entre sujeto y objeto; el quiasmo nos habla de ese entre que representa la encarnación de la subjetividad, es decir, la materialización del espíritu y la espiritualización de la materia. Tal entre se hace patente de manera clara en el tocar-como ya dijimos, tema predilecto para Nancy-. Para Merleau-Ponty, tocar es tocarse, pues no puedo tocar sin tocarme, no puedo sentir sin sentirme. Nuestro propio cuerpo es sensible y sintiente al mismo tiempo, pero sólo puede ser uno a través del otro, sólo en el tocar puedo sentirme, sin el tocar no podría tener idea de mi propio cuerpo y sus límites. Puedo decir que mi cuerpo siempre tiene estas dos caras o dos hojas, estos dos aspectos, el sensible y el sintiente: puedo en gran medida distinguirlos, pero al mismo tiempo sólo puedo saber de uno a través del otro y viceversa, sin uno el otro no podría aparecer.

Hablar de hojas es aún aplanar y yuxtaponer, bajo la mirada reflexiva, eso que coexiste en el cuerpo viviente. Si queremos metáforas, valdría mejor decir que el cuerpo sentido y el cuerpo sintiente son como el anverso y el reverso, o incluso, como dos segmentos de un solo recorrido circular, que por arriba va de izquierda a derecha y por abajo va de derecha a izquierda, pero que no es más que un solo 
movimiento en sus dos fases (Merleau-Ponty 1945, p. 1763).

Lo mismo pasa entre el mundo y mi cuerpo, entre uno y otro se abre un umbral de indiferenciación, un círculo en el cual no podemos saber de uno si no es a través del otro y viceversa: el mundo está en el cuerpo, tanto como el cuerpo está en el mundo. El quiasmo es una de las formas como se expresa esta ontología del entre que ya comienza a dibujarse en La estructura del comportamiento. Sin embargo, el carácter relacional, quiasmático entre organismo y medio quedará abiertamente ligado a Uexküll en el curso que Merleau-Ponty dio en el Collège de France entre 1957 y 1958. En esta ocasión, el francés retoma y problematiza el concepto de Umwelt de Uexküll, con la finalidad de acentuar el carácter circular o estructural de la relación entre el organismo y el medio. En particular hablando del hombre, para Merleau-Ponty está claro que entre el ser humano y el universo no hay una relación ni lineal ni determinista, que el ser humano no crea su medio en total libertad y que éste no estructura al hombre de manera unívoca, sino que entre ambos hay una relación estructural, es decir, que ambos se realizan en el encuentro, en el entre, de la misma manera que no sabemos cómo sonará una melodía sino hasta que todos los instrumentos la ejecutan, sabiendo que no sonará igual si es tocada por uno solo o por dos de ellos, con lo cual, cada nueva interpretación nunca será igual a la anterior: "El universo humano no es el producto de la libertad en el sentido kantiano, es decir, una libertad que está basada en una decisión; es más bien una libertad estructural” (Merleau-Ponty 1995, p. 178).

Siguiendo trazas kantianas, la obra de Uexküll es también un argumento anti-antropocentrista a partir del cual el mundo ya no puede reducirse al mundo humano, y si pudiéramos hablar de un mundo en sí tendríamos que reconocer al menos dos cosas: que no es equivalente al mundo humano y que este último es una de tantas perspectivas sobre el mismo, es decir, uno de tantos mundos tal y como vivientes hay. Cada mundo es, en este sentido, el mundo al que cada viviente se dirige. Este mundo circundante es -de acuerdo a la lectura que Merleau-Ponty hace del Umwelt uexkülliano- una realidad intermedia entre lo absoluto y lo objetivo.

El Umwelt marca la diferencia entre el mundo tal y como existe en sí y el mundo de tal o tal otro viviente. Es una realidad intermedia entre el mundo que existe para un observador absoluto y un dominio puramente subjetivo. Es el aspecto del mundo en sí al que el animal se dirige, que existe por el comportamiento de un animal, pero no forzosamente para su conciencia, es el entorno del comportamiento "opuesto al entorno geográfico" [...] (Merleau-Ponty 1995, p. 220).

El entorno geográfico -o Umgebung en términos de Uexküll- sería en gran medida ese mundo en sí que nos es inaccesible porque sólo habitamos una parcela de él, aquella que nos es significativa. Así como en Uexküll ese Umwelt está poblado de portadores de significado para este u otro viviente portadores que se relacionan tanto con las percepciones como con las acciones de los organismos, es decir, que son producto de un círculo funcional- ${ }^{7}$, en Merleau-Ponty el Umwelt es producto del comportamiento del viviente y, de igual forma, el comportamiento del viviente no puede entenderse ni puede tener lugar fuera de ese mundo circundante. Es precisamente con el concepto de comportamiento que Merleau-Ponty quiere dar cabida, entre otras cosas, a dos elementos que recorren buena parte de su propuesta filosófica:

1) El carácter relacional de todo organismo, es decir, que las pautas, respuestas y reacciones de todo viviente no son producto de una incidencia determinista del exterior sobre el medio interior, ${ }^{8}$ sino de la manera particular como éste se relaciona o entra en

\footnotetext{
${ }^{7}$ Por circulo funcional habría que entender el proceso por el cual el organismo se da un mundo circundante, a la vez que se conforma a sí mismo. Uexküll se refiere a un proceso circular en el cuál-idealmente- lo primero es la percepción de un objeto externo que por ello se vuelve significativo y, lo segundo, la respuesta del organismo frente a tal percepción en forma de acción sobre él: "Así, a todo acto que consiste en percibir y actuar, imprime al objeto carente de relaciones su significación y le transforma, por tanto, en un portador de significación en relación con el sujeto en el mundo circundante correspondiente. / Puesto que todo acto comienza con la producción de un signo perceptivo y termina con la creación de un signo de efecto en el mismo portador de significación, puede hablarse de un círculo funcional que une al portador de significación con el sujeto" (Uexküll 1942, pp. 28-29).

${ }^{8}$ Concepto acuñado por Claude Bernard para dar cuenta del ambiente interno de cada ser vivo -en particular se refería a la sangre- que contiene todas las sustancias que lo alimentan. Este medio interior permite a los animales ser independientes y sostener un equilibrio
} 
composición con esta realidad exterior y con su propia estructura interna; en otros términos, no habría hechos físicos brutos y neutros, sino sólo señales que han sido percibidas e interpretadas por el organismo, sin que en ello tenga que mediar una conciencia o una actividad intelectiva: "así, la excitación no sería nunca el registro pasivo de una acción exterior, sino una elaboración de estas influencias que son sometidas a las normas descriptivas del organismo" (Merleau-Ponty 1942, p. 28). Con lo cual...

2) Ninguna reacción o maniobra del viviente puede ser vista como una respuesta localizada o aislada de algún punto del organismo, sino tiene que ser ver vista desde una perspectiva holista, como la participación y el acoplamiento del organismo con su mundo circundante y, a la vez, del organismo consigo mismo en una totalidad.

Merleau-Ponty no dejará de reconocer en Uexküll, y en particular en el concepto de Umwelt, el antecedente de su noción de comportamiento. En ambos casos, el organismo es explicado dejando de lado los esquemas mecánico-deterministas y reconociendo su carácter relacional, pues sólo puede hablarse de organismo como una relación y un contrapunto entre éste y su totalidad interna, así como con su mundo circundante. Desde esta perspectiva, la propia conciencia pierde su lugar central y aunque sigue siendo vista como algo que instituye sentido, tal institución sólo puede darse en su contrapunto con el exterior, es decir, en un entre y no en un polo puntual y separado. Ahora bien, tal institución de sentido, tal facultad de dirigirse al mundo para poblarlo de significados, no sería atributo ni esencial ni exclusivo de la conciencia, el cuerpo y en general toda forma de comportamiento llevan a cabo también tal institución. A ojos de Merleau-Ponty, Uexküll está señalando a toda una tradición, cuyo artífice más claro es Descartes, que ha separado de manera casi irreconciliable el mundo material y mecánico del exterior, del mundo subjetivo y espiritual de la conciencia. Frente a lo que considera una simplificación dicotómica, el biólogo estonio trata de conciliar ambos polos no mediante una síntesis dialéctica que presupondría que ambos existen previamente a su encuentro, sino apostando por el encuentro mismo: sería el contrapunto aquello que puede decirnos algo tanto de la conciencia como del mundo, es decir, en términos merleaupontyanos, sería el comportamiento lo que puede dejarnos un índice de que existe tanto el sujeto como el mundo: "La estructura del comportamiento, tal y como se ofrece a la experiencia perceptiva, no es ni cosa ni consciencia y eso es lo que la vuelve opaca a la inteligencia” (Merleau-Ponty 1942, p. 138). Así, el comportamiento expresa la forma como cada viviente vuelve significativo el entorno geográfico o Umgebung, en sí mismo desposeído de cualquier señal o portador de significado, pero esta tarea no es exclusiva de la conciencia; es decir, el comportamiento no se reduce a ser un acto de la conciencia, se expresa, antes bien, en tres distintos órdenes de significación igualmente importantes: la materia, la vida y el espíritu. En cada uno de esos órdenes el comportamiento no surge privilegiadamente del sujeto ni es producto de las solas directrices del exterior, sino se ubica en un entre en el cual el sujeto y el mundo se configuran de manera mutua, relacional. El comportamiento, es decir, la manera como el viviente se relaciona con el mundo, como lo vuelve significativo y la manera como responde a él en tanto totalidad, es precisamente la forma que toma el entre en la obra merleupontyana.

Uexküll anticipa la noción de comportamiento. Para él, cuando se habla del Umwelt no se trata de una especulación psicológica. Hay maneras de comportarse del animal que se comprenden y que pueden ser leídas en el sentido de un comportamiento. Esta actividad comportamental orientada hacia el Umwelt comienza mucho antes de la invención de la conciencia: desde el momento en que se tienen estímulos que actúan, no por la simple presencia física, sino en tanto un organismo está dispuesto a recibirlas y a tratarlas como señales. La conciencia no es más que una de las formas variadas del comportamiento, ella no debe ser definida desde el interior, desde su punto de vista, sino sólo la aprehendemos a través de los cuerpos de los otros, no como una forma centrífuga, sino como un mundo cerrado donde los estímulos externos se le aparecen como fuera de ella. La conciencia debe aparecer como una institución, como un tipo de comportamiento (Merleau-Ponty 1995, p. 220).

autónomo frente al exterior gracias a las operaciones metabólicas y auto- reguladoras que dicho medio permite. Con este concepto nos referimos así a los "mecanismos fisiológicos por medio de los cuales el organismo se adapta a un medio exterior manteniendo su unidad [...]” (Prochiantz 1990, p. 35). 
Ni cosa ni espíritu, para el filósofo francés el comportamiento responde más bien a una forma, es decir, a una composición o contrapunto de fuerzas que de manera dinámica alcanza cierto equilibrio, pero sólo para lanzarse a una nueva configuración. En este cambio constante que pone en relación elementos que en primera instancia parece que tienen poco que ver, cada cambio local va a reflejarse en una redistribución del todo, incluidas aquellas fuerzas que fueron puestas originariamente en relación. Dicha reconfiguración no respondería a ninguna ley ni a ningún elemento trascendente o trascendental, ni el mundo físico ni la consciencia podrían dictar sus reglas, antes bien, éstas son inmanentes a la dinámica del sistema, con lo cual, los cortes y las discontinuidades son perfectamente armónicas en tanto son producidas por dicha dinámica y tal y como ocurre con una melodía. Un cambio en tal configuración, resultará en un cambio de las partes mismas, pues todo se resuelve no en los puntos que se relacionan, sino en la relación misma, en el entre.

Pensemos por ejemplo en la enfermedad, los ejemplos a los que recurre Merleau-Ponty en La estructura del comportamiento deben mucho a Goldstein como ya hemos apuntado. Cuando enfermamos, ¿respondemos de la misma manera que los demás frente a la misma enfermedad?, ¿nosotros mismos respondemos de la misma manera al mismo padecimiento en momentos diferentes de nuestra vida? La respuesta es claramente negativa. Muy cercano a las posturas de Georges Canguilhem (1943), para Merleau-Ponty enfermar no es solamente estar menos sano, implica más bien una respuesta de todo el organismo, del comportamiento, que nos arroja a vivir de otra forma, en otro ritmo vital: somos otros cuando enfermamos y no meramente menos de lo que éramos. El comportamiento se transforma de tal manera que nosotros y nuestro mundo circundante también lo hacen, en tanto su significado, es decir, sus relaciones, ya no son las mismas.

En suma, así como en Uexküll no hay propiamente ni sujeto ni mundo como polos absolutos, en Merleau-Ponty el esquema se repite, pero esta vez el concepto clave es relacional en sí mismo: el comportamiento. Podría pensarse que todo comportamiento es la acción de un sujeto, pero con tal noción el filósofo francés hace énfasis en el carácter relativo del mismo: un comportamiento es el resultado de la manera como las partes de un sistema entran en relación, en el entendido que las partes no existen de manera previa a las relaciones que entablan. La enfermedad, en este sentido, sería una configuración particular, una manera particular de significar y de poner en relación elementos que no estaban antes ahí. "El comportamiento está hecho entonces de relaciones, [...] el comportamiento no es una cosa, pero no es tampoco una idea, no es la envoltura de una pura consciencia y, como testimonio de un comportamiento, yo no soy una pura consciencia" (Merleau-Ponty 1942, p. 138).

El comportamiento sería a cada momento la configuración de las relaciones que lo hacen posible: del viviente con el mundo circundante y de las partes que componen su organismo. La fenomenología merleaupontyana da lugar, así, a una ontología que se pregunta por la manera y los procesos a través de los cuales los sujetos, los objetos y el mundo emergen en un plexo significativo, como efecto de procesos de significación. Lo peculiar de esta propuesta onto-fenomenológica es que en ningún momento soslaya su fundamento biológico y naturalista; los ejemplos de la biología, la medicina, la etología, la psicología, entre otras ciencias, no cesan de respaldar este peculiar acercamiento. Esta ontología tiene sin duda una base naturalista y bien podríamos hablar de que en su obra se expresa una cierta ontología naturalizada. En esta empresa muchos conceptos y metáforas uexküllianas contribuyeron a dar cuenta de una ontología relacional donde el ser sólo puede acontecer en el entre.

\section{CODA: una ontología del entre}

La huella que la obra de Jacob von Uexküll dejó en la de Merleau-Ponty resulta innegable. Conceptos como Umwelt y Melodie son retomados por el filósofo francés desde su libro de 1942. Sin embargo, en trabajos y cursos posteriores -sobre todo los impartidos en el Collège de France entre 1957 y 1958- se hace patente una lectura más amplia y concienzuda de la obra del filósofo estonio. Es sobre todo el concepto de Umwelt el que más influencia tendrá en la manera cómo Merleau-Ponty trata de establecer las bases de una perspectiva onto-fenomenológica distinta, una que no parte de orígenes claros y 
distintos, como sería el caso de la conciencia o de una concepción sustancialista del sujeto, sino que parte de una forma que sólo puede ser explicada por sus relaciones, por su comportamiento. En este rubro la noción de melodía vuelve a ser otro de los elementos uexküllianos que impactan el pensamiento del francés: la naturaleza sería una composición musical hecha por el punto y contrapunto de notas que sólo cobran forma en le ejecución de la melodía. El entre, la coincidencia entre dos notas, daría a cada una su razón de ser y no al revés. Es la melodía como un todo, como encuentro y contrapunto de sonidos, lo que da a cada nota una realidad concreta. Sin duda estamos, tanto en la obra del estonio como en la del francés, ante una configuración ontológica distinta, una fincada en la relación, en el encuentro, la coincidencia o el contrapunto, en ese entre a partir del cual los polos, los sujetos y los elementos puntuales pueden cobrar consistencia.

Tanto Uexküll como Merleau-Ponty fundaron sus propuestas biológico-filosóficas no en una ontología basada en sujetos o en organismos puntuales, sino fundada en relaciones, en el entre que hace posible la definición de sujetos y organismos concretos. Esta preponderancia del entre significó, en particular en el caso de Uexküll, haber hecho énfasis en las señales, en los portadores de significado, en los procesos de significación que tanto definen al medio que habita cada viviente, como contribuyen a conformar la estructura de cada organismo, a la vez que hizo posible concebir mundos intersubjetivos donde se traslapan y comparten señales y mensajes. Como lo expone Rüting (2004), tal esquema dibuja un panorama biológico diferente al que hicieron postularon perspectivas de cariz más mecanicista, en tanto hizo posible pensar en subjetividades diferentes a la humana y reconocer una interdependencia significativa entre los organismos, argumentos que se mostraron claramente contrarios a algunas perspectivas modernas, empecinadas en el antropocentrismo y en entablar analogías entre vivientes y máquinas. $^{9}$ En este punto el legado de Uexküll es de enorme importancia, pues aunque en su obra jamás aparece el término "Biosemiótica" -el concepto es acuñado hasta 1961-, sus trabajos fundaron los cimientos de esta perspectiva tanto etológica como ontológica que introduce una concepción innovadora de la naturaleza en tanto sistema de signos.

\section{Bibliografía}

Barbieri, M. (2008), Introduction to Biosemiotics: The New Biological Synthesis, Dordrecht: Springer.

Berofsky, B. (1999), “Determinism”, en R. Audi (ed.), The Cambridge Dictionary of Philosophy, Cambridge: Cambridge University Press, pp: 228-229.

Brentari, C. (2011), Jacob von Uexküll: The Discovery of the Unwelt between Biosemiotics and Theoretical Biology, New York: Springer.

Buchanan, B. (2008), The Animal Enviroment of Uexküll, Heidegger, Merleau-Ponty, and Deleuze, New York: Suny.

Canguilhem, G. (1943), Le normal et le pathologique, Paris: Puf.

Castro García, O. (2009), El concepto de Umwelt y el origen de la biosemiótica, Tesis de doctorado, Barcelona: Universidad de Barcelona.

Favareau, D. (2010), Essential Readings in Biosemiotics: Anthology and Commentary, New York: Springer.

Goldstein, K. (1951), La structure de l'organisme, Paris: Gallimard.

Kennedy, M., Kennedy, J. y T. Rutherford-Johnson (2013), The Oxford Dictionary of Music, Oxford: Oxford University Press.

Merleau-Ponty, M. (1995), La nature. Cours au Collège de France, Paris: Seuil.

Merleau-Ponty, M. (1945), Phénoménologie de la perception, Paris: Gallimard.

\footnotetext{
9 Para Marcelo Barbieri este linaje mecanicista abarca desde "[...] Galileo, Descartes, Newton, Lamarck, Darwin, Mendel, James Watson, Francis Crick y Jacques Monod, un acercamiento que ha producido lo que aún hoy es el paradigma central de la biología moderna" (Barbieri 2008, p. 102).
} 
Merleau-Ponty, M. (1942), La structure de comportement, Paris: Puf.

Nancy, J.L. (2003), Corpus, Madrid: Arena.

Ostachuk, A. (2013), "El Umwelt de Uexküll y Merleau Ponty”, Ludus Vitalis 21(39): 45-65.

Prochiantz, A. (1990), Claude Bernard. La révolution physiologique, Paris: Puf.

Rüting, T. (2004), "History and Significance of Jacob von Uexküll and of his Institute in Hamburg”, Sign System Studies 32: 35-72.

Uexküll, J. (1956), Streifzuge durch die Umwelten von Tiete nuns Menschen, Hamburg: Rowohlt Taschenbuch Verlag.

Uexküll, J. (1942), Meditaciones biológicas. La teoría de la significación, Madrid: Revista de Occidente.

Uexküll, J. (1940), Bedeutungslehre, Leipzig: Verlag von J.A. Barth.

Uexküll, J. (1931), “Die Rolle des Subjekts in der Biologie”, Die Naturwissenschaften 19: 385-391.

Uexküll, J. (1930), Die Lebenslehre, Potsdam: Müller und Kiepenheuer Verlag.

Uexküll, J. (ed.) (1928), Natur und Leben, München: F. Bruckmann.

Uexküll, J. (1927), “Die Einpassung”, Handbuch der normalen und pathologischen Physiologie 1: 693-701.

Uexküll, J. (1926), Theoretical Biology, New York: Harcourt, Brace and Company.

Uexküll, J. (1922), Ideas para una concepción biológica del mundo. Ideas del siglo XX, Madrid: Calpe.

Uexküll, J. (1920), Biologische Briefe an eine Dame, Berlín: Paetel. (Traducción castellana de Tomás Bartoletti y Laura Cecilia Nicolás (2014), Cartas biológicas a una dama, Buenos Aires: Cactus)

Uexküll, J. (1913), Bausteine zu einer biologischen Weltanschauung, München: F. Bruckmann.

Uexküll, J. (1909), Umwelt und Innenwelt der Tiere, Berlín: Verlang von Julius Springer.

Uexküll, J. y G. Kriszat (1934), Streifzüge durch die Umwelten von Tieren und Menschen: Ein Bilderbuch unsichtbarer Welten, Berlin: Springer. 